Supporting Information

\title{
Point-of-Care test paper for exhaled breath aldehyde analysis via mass spectrometry
}

Zhengzhou Li, ${ }^{1,2}$ Yuze Li, ${ }^{1,2}$ Lingpeng Zhan, ${ }^{4}$ Lingwei Meng,,${ }^{1,2}$ Xi Huang, ${ }^{1}$ Tie Wang,,${ }^{1,2}$ Yafeng $\mathrm{Li}^{*}{ }^{1,3}$ and Zongxiu $\mathrm{Nie}^{* 1,2}$

${ }^{1}$ Beijing National Laboratory for Molecular Sciences, Key Laboratory of Analytical Chemistry for Living Biosystems, Institute of Chemistry, Chinese Academy of Sciences, Beijing 100190, China

${ }^{2}$ University of Chinese Academy of Sciences, Beijing 100049, China

${ }^{3}$ Current address: Children's Research Institute and the Department of Pediatrics, University of Texas Southwestern Medical Center, Dallas, Texas 75390, USA

${ }^{4}$ Institute of Cell Analysis, Shenzhen Bay Laboratory, Shenzhen 518132, China

*E-mail: znie@iccas.ac.cn; liyafeng@iccas.ac.cn. 


\section{Table of Contents}

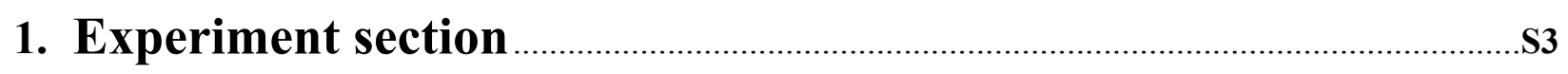

- Synthesis and characterization of 4-ATP capped AgNPs.................................................................33

- Gas-phase aldehyde capture process and thin film acceleration......................................................S3

- Thiol elution and paper spray MS detection ...............................................................................

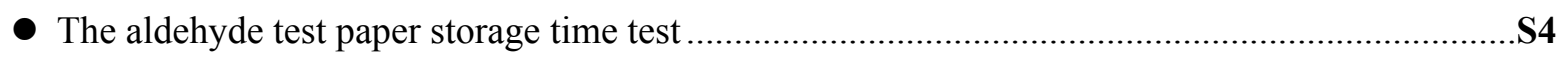

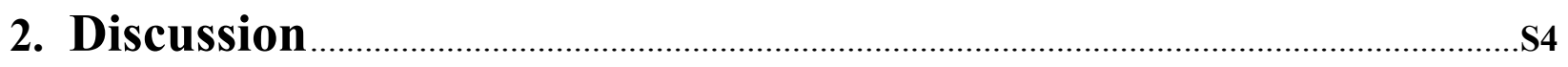

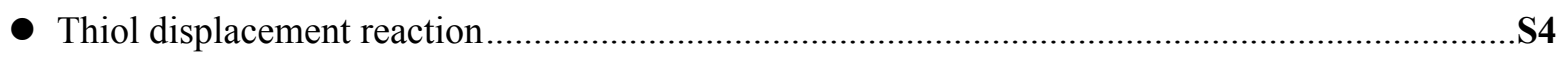

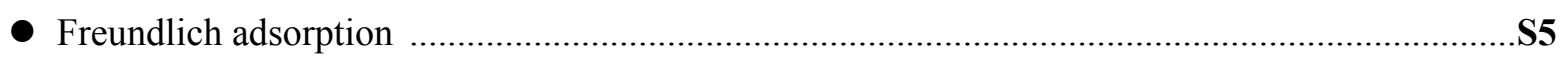

3. Supplementary figures and tables ……………………………………................

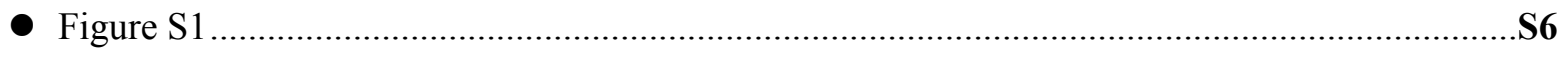

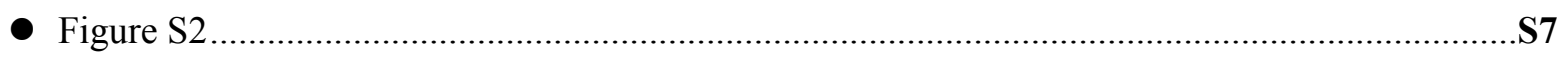

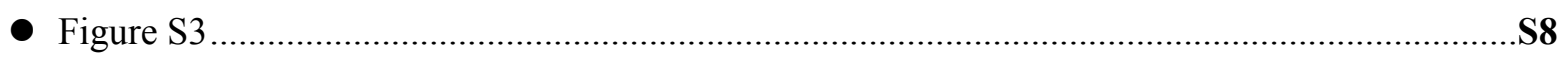

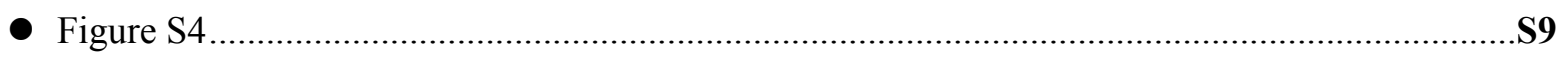

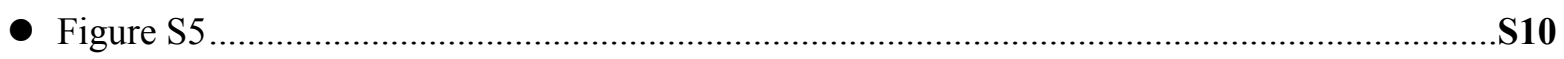

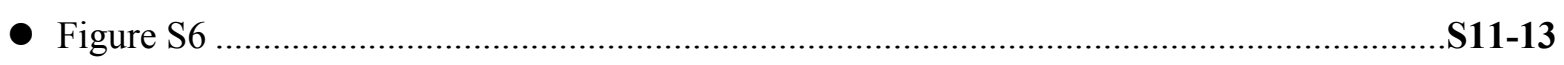

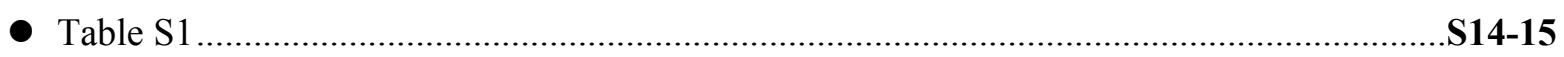

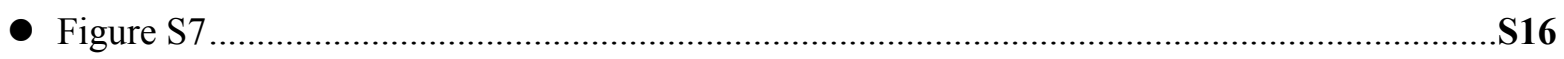

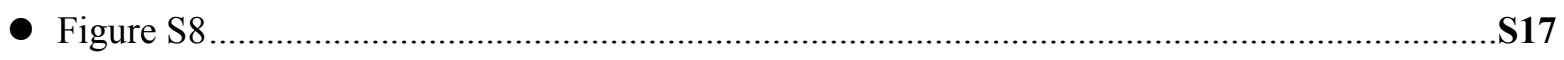

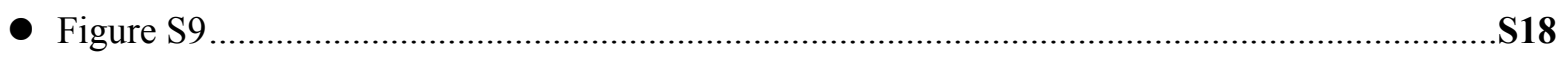

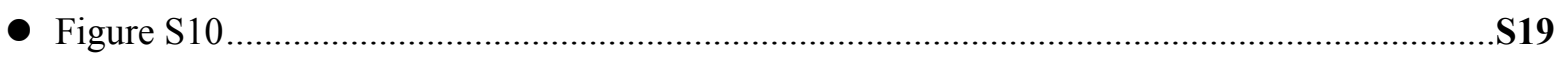

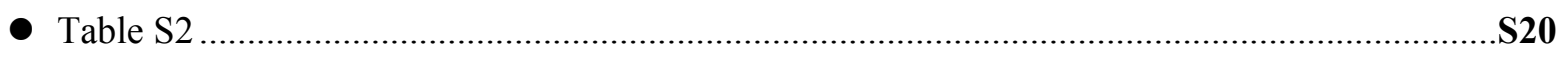

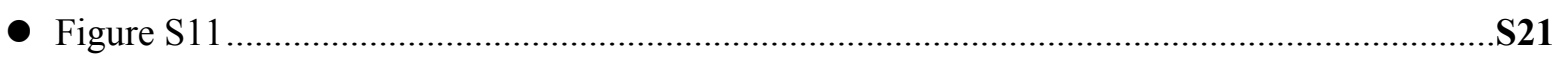

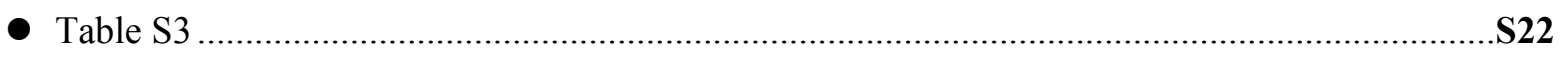

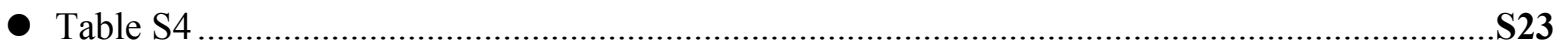

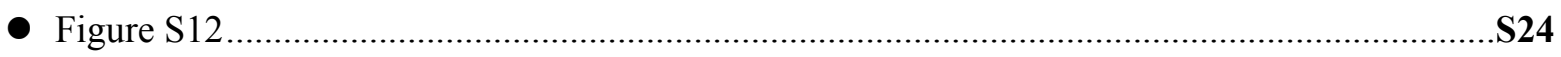

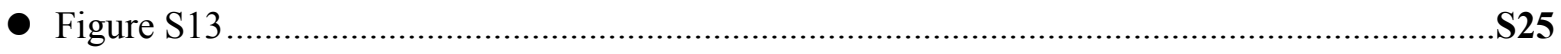

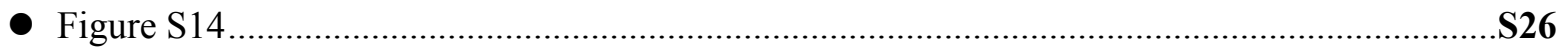

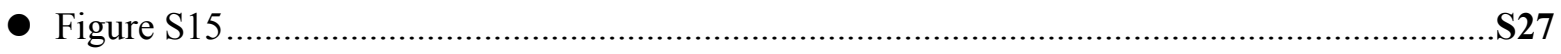

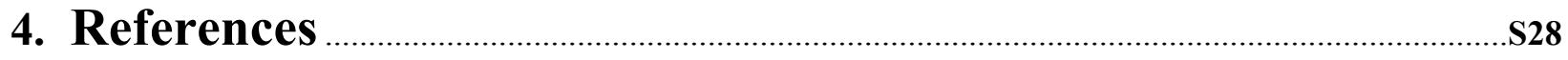




\section{EXPERIMENT SECTION}

\section{Synthesis and characterization of 4-ATP capped AgNPs}

The synthesis of 4-ATP capped AgNPs was carried out as previously reported ${ }^{1}$. Methanol solution of 4ATP $(5 \mathrm{mM}, 2 \mathrm{~mL})$ was added into $20 \mathrm{~mL}$ silver nitrate $(0.5 \mathrm{mM})$ solution under vigorous stirring. Freshly prepared aqueous sodium borohydride solution $(10 \mathrm{mM}, 400 \mathrm{~mL})$ was then added dropwise into the solution, also under vigorous stirring. The thus formed black brown silver colloids were centrifuged at $6000 \mathrm{rpm}$ for 5 min with a Millipore centrifugal filter device (MWCO, $100 \mathrm{kDa}$ ). The suspension was removed and the 4ATP capped AgNPs were reconstituted in water with a concentration factor of 10 . The final concentration of the colloid was about $10.8 \mathrm{mg} / \mathrm{L}$.

The 4-ATP AgNPs colloid was characterized by transmission electron microscopy [TEM; JEM-1011; JEOL, Tokyo, Japan] and X-ray photoelectron spectroscopy [XPS; ESCALAB250XI; TMO, NY, USA]. The aldehyde test paper was characterized by scanning electron microscopy [(SEM; S-4800; Hitachi, Tokyo, Japan].

\section{Gas-phase aldehyde capture process and thin film acceleration}

For the testing of aldehyde standards, sealed Centrifuge Tubes $(50 \mathrm{~mL})$ were used. Methanol solution of a certain concentration of $30 \mu \mathrm{L}$ of benzaldehyde and p-tolualdehyde was dropped into the tube first and kept in incubator $\left(37^{\circ} \mathrm{C}\right)$ for $2 \mathrm{~h}$ to let the aldehydes evaporate and form gas-phase aldehydes atmosphere. Then the aldehyde test paper was placed in the tube and the tube was kept in an incubator with constant temperature for a certain period of time. The influence of incubation time and temperature was evaluated and the results are shown in Figure S12.

To introduce thin film acceleration in the aldehyde capturing process, $10 \mu \mathrm{L}$ methanol was added on the aldehyde test paper before it was placed into the tube.

\section{Thiol elution and paper spray MS detection}

After gas-phase aldehyde capture process, the aldehyde test paper was taken out from the tube, attached to a copper alligator clip, and placed about $5 \mathrm{~mm}$ away from the MS inlet. Then $25 \mu \mathrm{L}$ methanol solution of $0.02 \mathrm{M}$ 1-dodecanethiol (in elution solution optimization experiment different thiols with a series of concentration conditions were used) was added on the paper substrate as eluent and spray solution. DC voltage $+3.5 \mathrm{kV}$ was applied for paper spray and the MS inlet capillary temperature was kept between 270$290{ }^{\circ} \mathrm{C}$. (As MS inlet capillary temperature had been reported to have influence on reaction rate ${ }^{2}$, optimization of this parameter was done and shown in Figure S13) 


\section{The aldehyde test paper storage time test}

For storage time test, the same procedure was taken as quantitative analysis. $10 \mathrm{ppb}$ benzaldehyde and $100 \mathrm{ppt}$ IS were spiked for this test. After sampling process, the aldehyde test paper was directly put into refrigerator and stored at $-20^{\circ} \mathrm{C}$. After a certain period of time, the paper was taken out and detected by MS in MRM mode.

\section{DISCUSSION}

\section{Thiol displacement reaction}

In our method we used thiol displacement reaction to elute imine product of 4-ATP and aldehydes by 1 dodecanethiol. We believe that the thiol displacement reaction occurred during paper spray ionization procedure is mainly driven by thermodynamical mechanism. As figure S4 and S5 show, the MS intensity of imine product ion $(\mathrm{m} / \mathrm{z}=214)$ is elevated as the concentration of 1-dodecanethiol increases and the MS intensity reaches the highest when $0.02 \mathrm{M} 1$-dodecanethiol methanol solution is used as eluent. Under this condition, the quantity of 1-dodencanethiol molecule is much more than 4-ATP molecule, therefore, the thiol replacement reaction is more likely to occur and the MS intensity of the imine product reaches the top. As the concentration of 1-dodecanethiol continues to increase, the MS intensity of the imine product declines. The reason is probably that owing to the high surface affinity of 1-dodecanethiol, the excess thiols will take up the surface charging site of the droplet generated by paper spray and suppress the ionization of the target molecules. In order to further verify our hypothesis. We did an experiment comparing the thiol displacement reaction using online paper spray ionization and offline nanoelectrospray ionization (nanoESI) respectively. For online experiment DC voltage was applied while no DC voltage was applied for offline experiment (1-dodecanethiol was added on the paper without DC voltage applied and the eluent was collected and detected). As is shown in Figure S14, without DC voltage, thiol displacement reaction could also occur. The result shows that thermodynamically driven mechanism is the main reason for thiol displacement reaction. 


\section{Freundlich adsorption}

Freundlich equation describes the adsorption of a quantity of gas adsorbed by unit mass of solid. The expression of Freundlich adsorption equation is

$$
\frac{x}{m}=K_{f} c^{\frac{1}{n}}
$$

Where $x$ represents weight of the particles adsorbed by ' $m$ ' grams of the adsorbent. The ratio, $x / m$, represents the quantity of particles adsorbed by the adsorbents per gram (unit mass)., $\mathrm{K}_{\mathrm{f}}$ is the Freundlich constant or maximum adsorption capacity, $C$ is the solution concentration equilibrium $(\mu \mathrm{mol} / \mathrm{L})$. The index $1 / n$ is the measure of intensity. As the amount of adsorbent (4-ATP caped AgNPs) is certain throughout all the tests, and we use intensity ratio of the target ion and internal standard ion to reflect the amount of the test sample, the equation can be simplified to the following:

$$
\text { Intensity ratio }=K^{\prime} c^{\frac{1}{n}}
$$

Where $\mathrm{K}^{\prime}$ represents apparent $\mathrm{K}$.

In the case of benzaldehyde detection, the result is shown in Figure $5 b$, the final equation is;

$$
\text { Intensity ratio }=3.1524 c^{0.1116}
$$

corresponding to $K^{\prime}=3.1525,1 / n=0.1116$.

It is proved that the maximum adsorption capacity of the aldehyde test paper excesses the linear range of the quantitative curve in the detection of gas-phase benzaldehyde. (Figure S15) 


\section{Supplementary figures and tables}

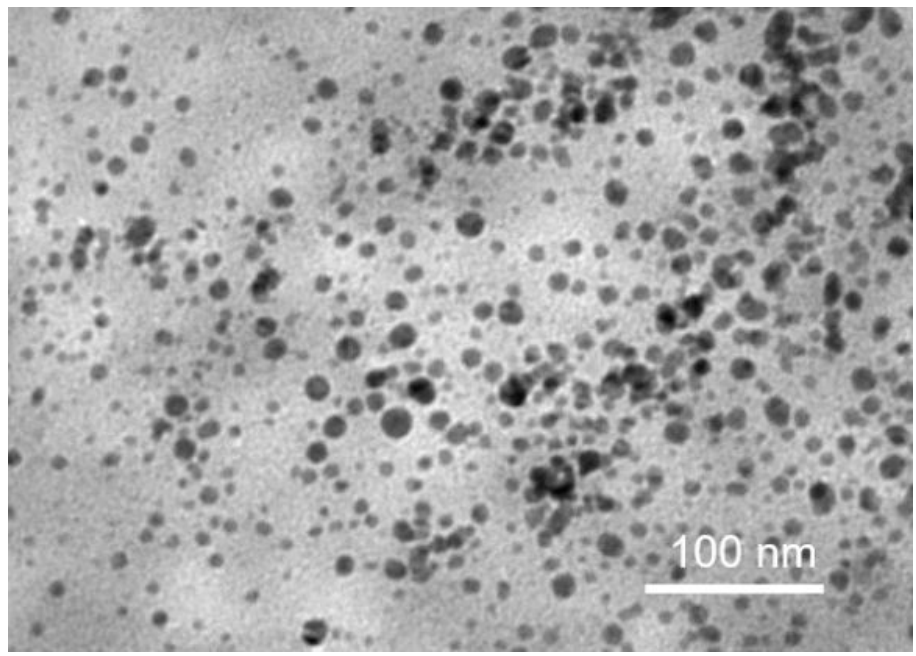

Figure S1. Transmission electron microscope (TEM) images of 4-ATP capped AgNPs with an average diameter of $8.1 \mathrm{~nm}$. 

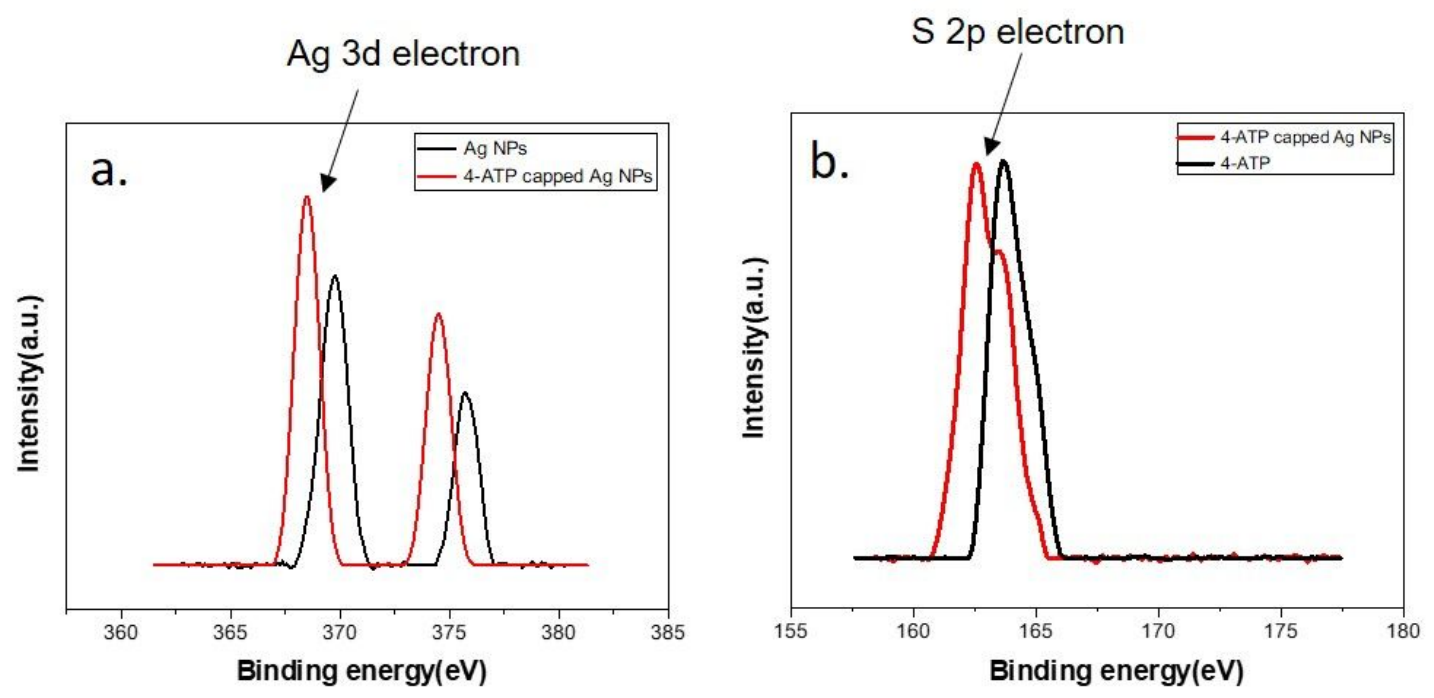

Figure S2. XPS spectrum of a) Ag 3d electrons of bare AgNPs (black line) and 4-ATP capped AgNPs (red line), the shift of the binding energy is from $369.8 \mathrm{eV}$ to $368.5 \mathrm{eV}$. b) S $2 \mathrm{p}$ electrons of 4-ATP (black line) and 4-ATP capped AgNPs (red line), the shift of the binding energy is from $163.7 \mathrm{eV}$ to $162.6 \mathrm{eV}$. The XPS result indicates the successful loading of 4-ATP onto the AgNPs. 


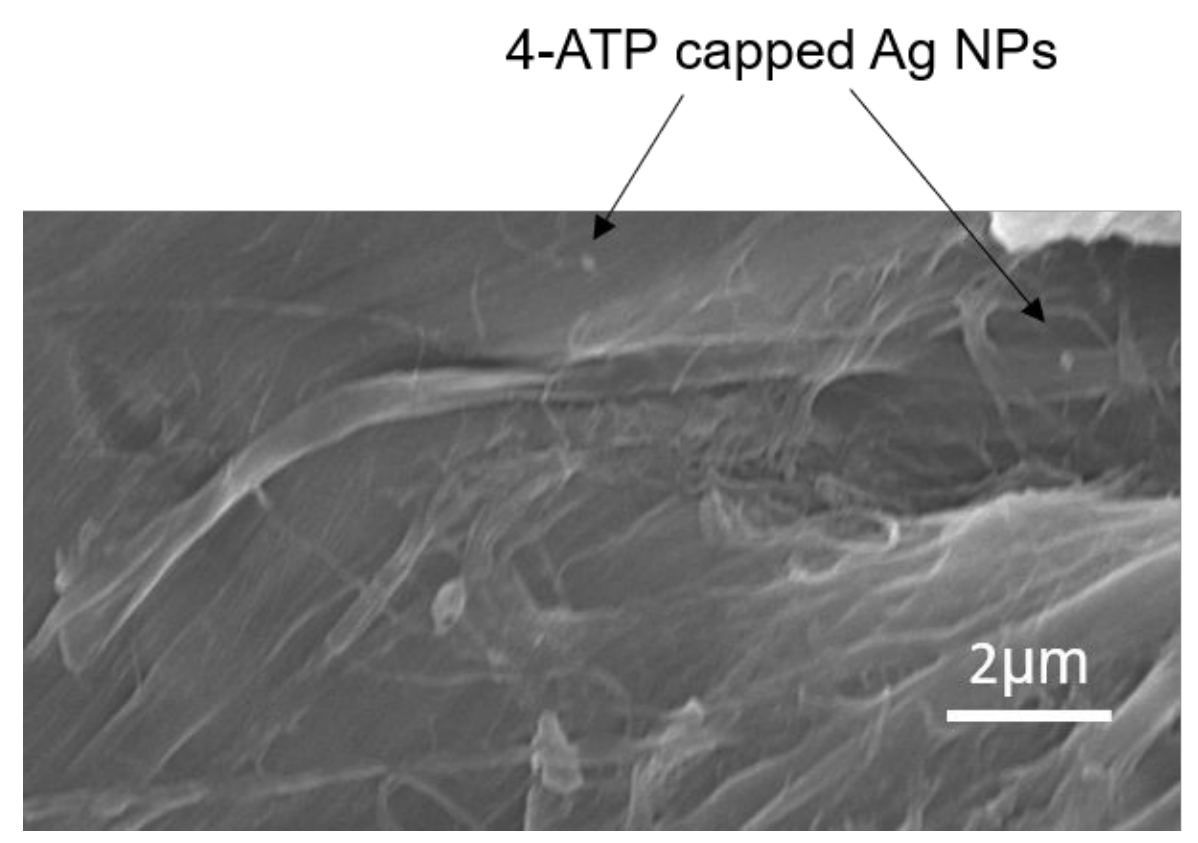

Figure S3. Scanning electron microscope (SEM) images of 4-ATP capped AgNPs on chromatography paper. 

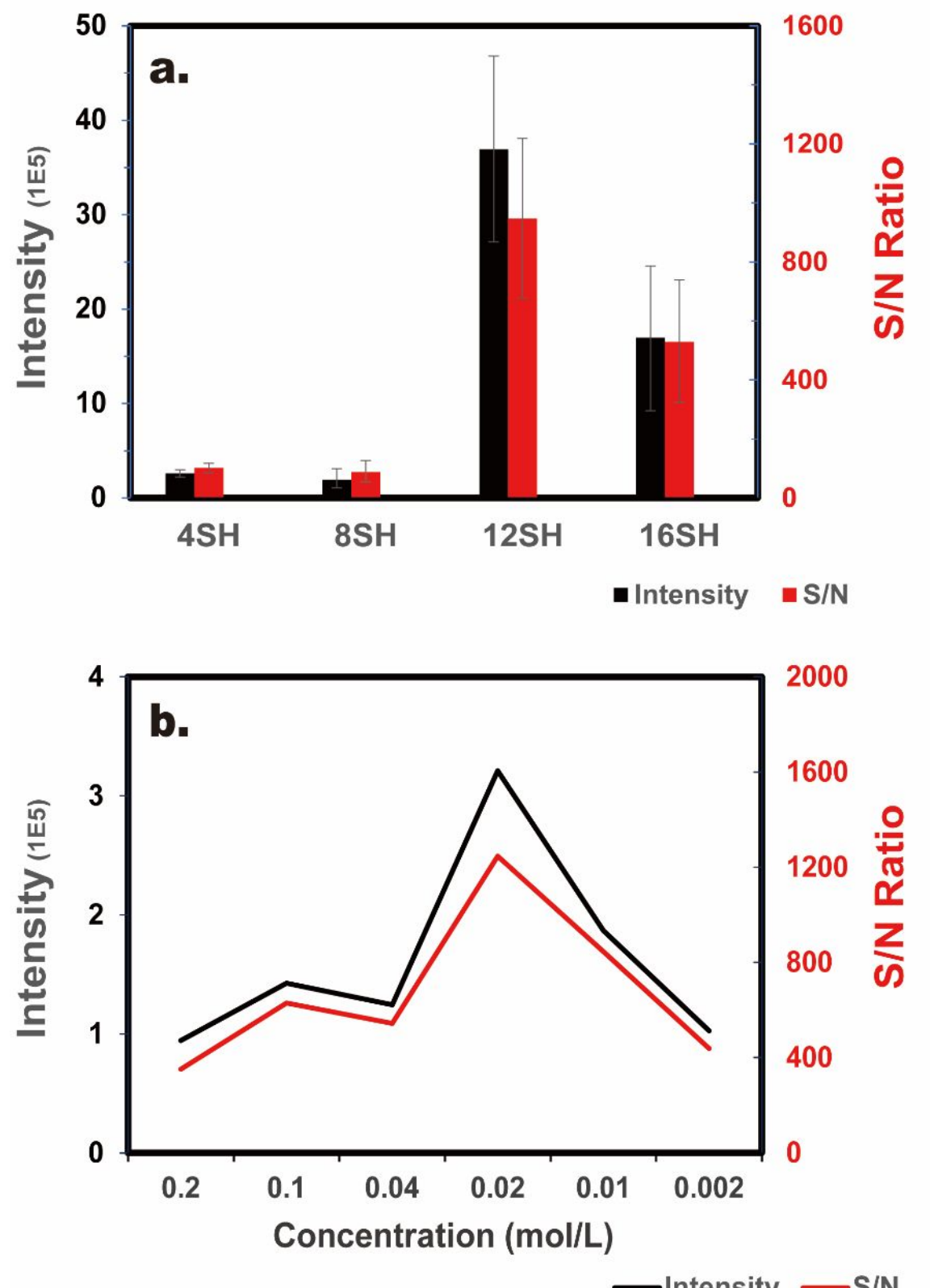

Figure S4. Elution and spray solution optimization. (a) Comparison of 1-butanethiol (4-SH), 1-octanethiol (8-SH),1-dodecanethiol (12-SH), and 1-hexadecanethiol (16-SH) with concentration of $0.02 \mathrm{M}$ as eluent and spray solution. The signal intensity of the reaction product of benzaldehyde and 4-ATP when using 12-SH as elution and spray solvent is the highest. (b) Using 12-SH with different concentrations as eluent and spray solution. The sample tested was gas-phase benzaldehyde (1 ppm). 

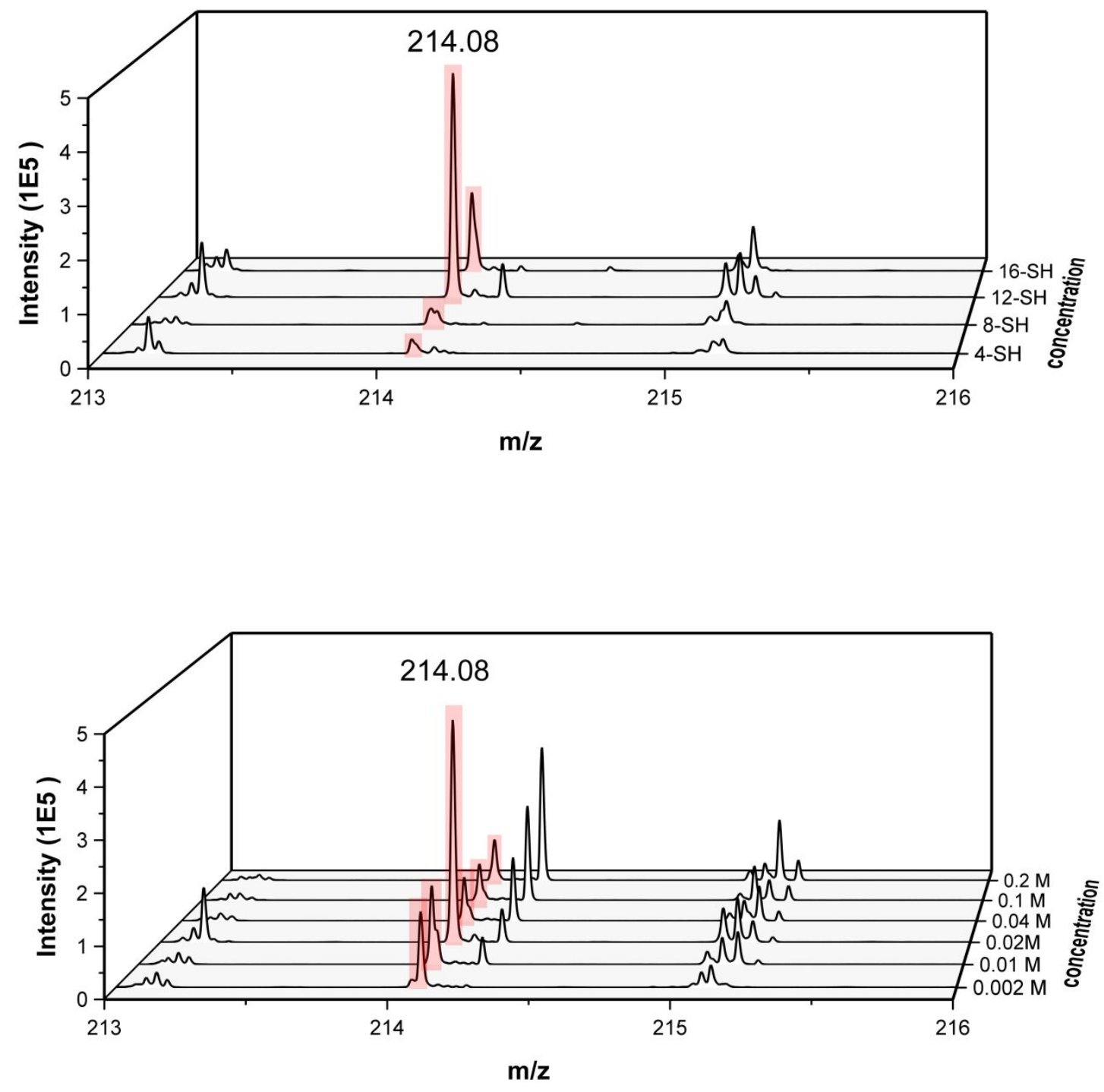

Figure S5. Corresponding mass spectra of Figure S4. 
Formaldehyde 138
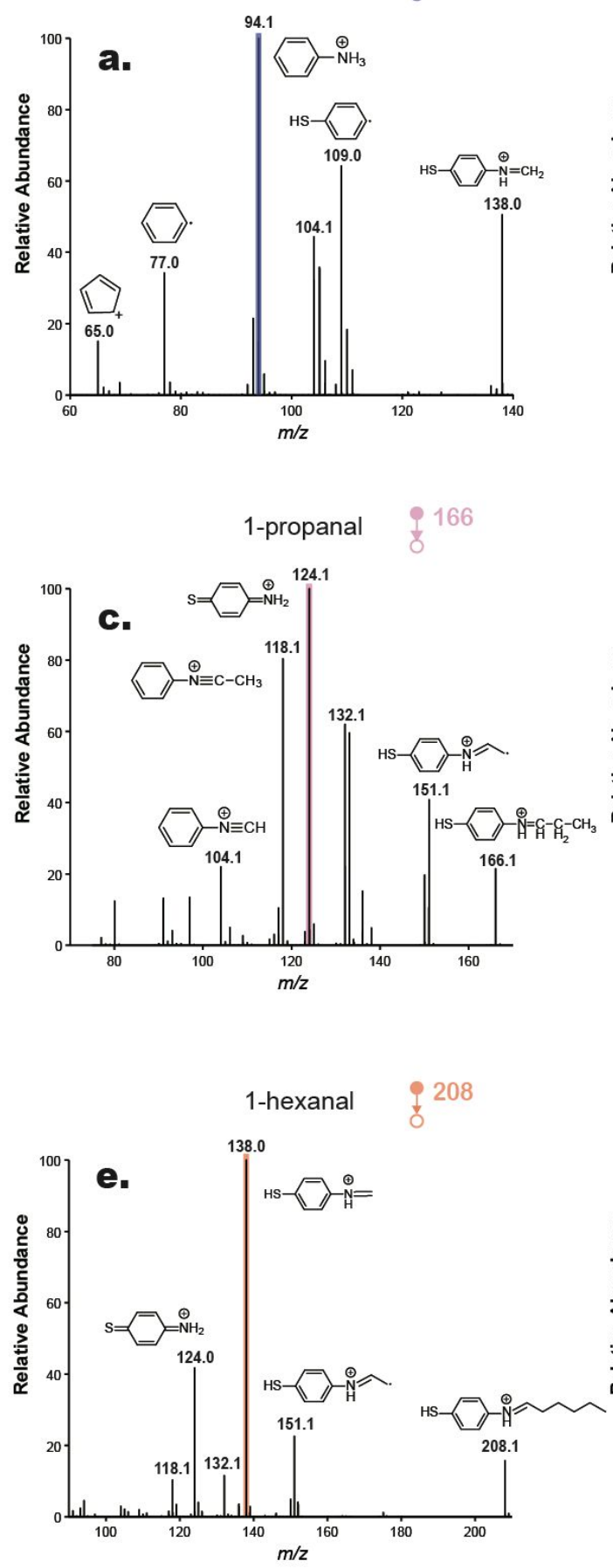
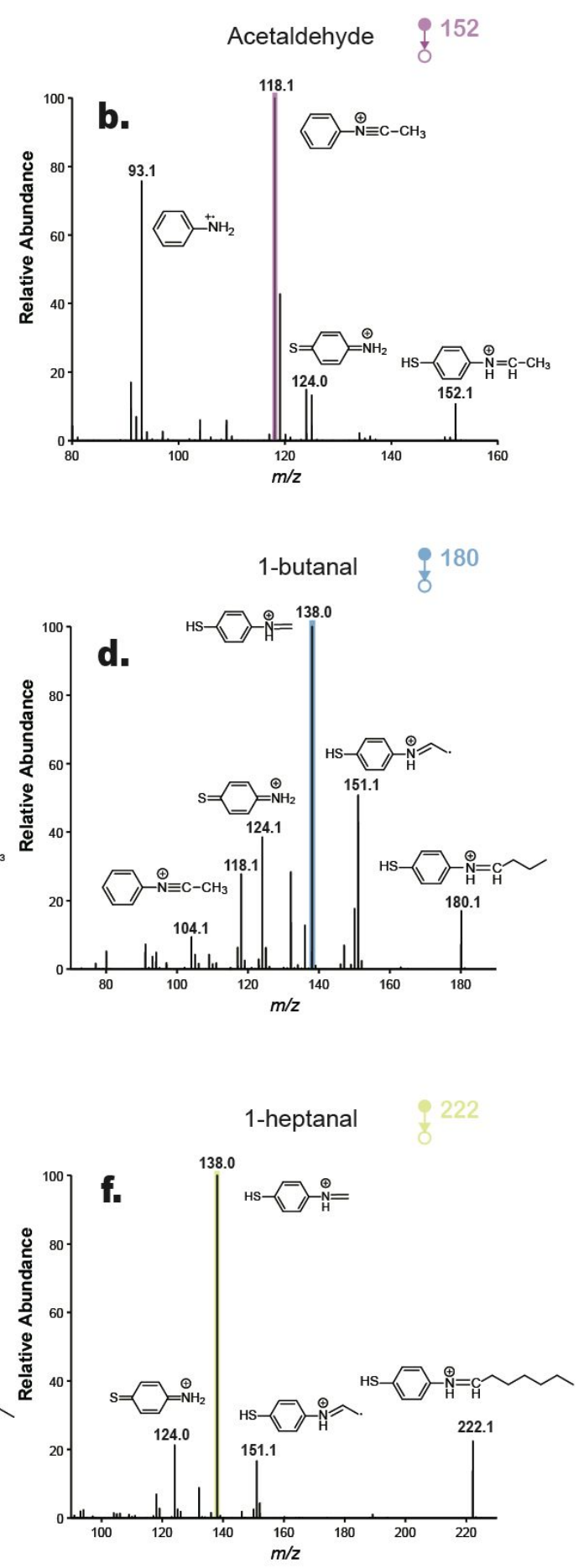

Figure S6-1. MS/MS spectra of (a) $m / z 138.0$ in the detection of formaldehyde. (b) $m / z 152.1$ in the detection of acetaldehyde. (c) $\mathrm{m} / \mathrm{z} 166.1$ in the detection of 1-propanal. (d) $\mathrm{m} / \mathrm{z} 180.1$ in the detection of 1-butanal. (e) $m / z 208.1$ in the detection of 1-hexanal. (f) $m / z 222.1$ in the detection of 1-heptanal. The precursor ion is produced by Schiff base reaction of 4-ATP and corresponding gas-phase aldehyde molecule (1000 ppm). 

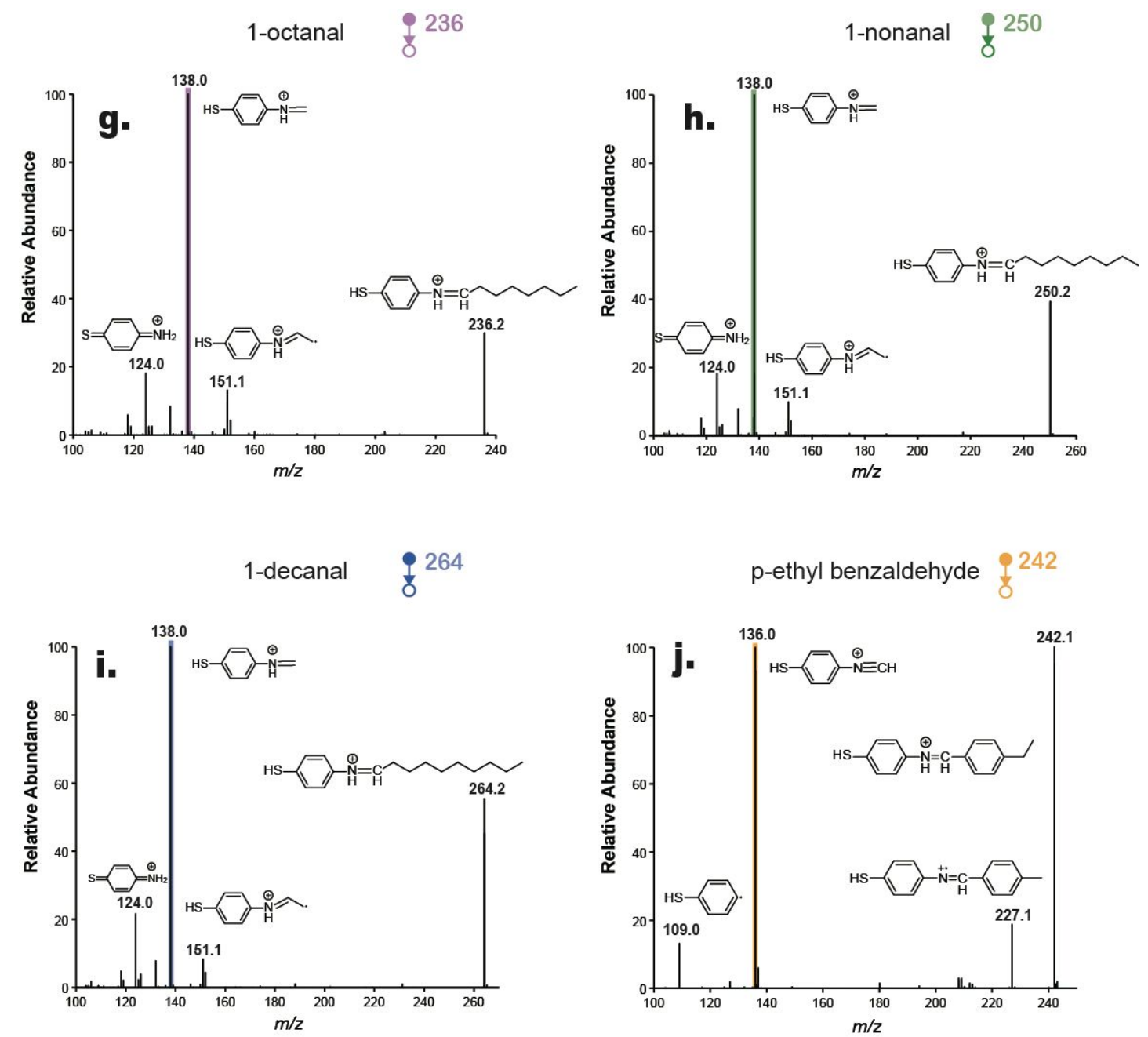

Figure S6-2. MS/MS spectra of (h) $m / z 236.2$ in the detection of 1-octanal. (h) $m / z 250.2$ in the detection of 1-nonanal. (i) $\mathrm{m} / \mathrm{z} 264.2$ in the detection of 1-decanal. (j) $\mathrm{m} / \mathrm{z} 242.1$ in the detection of p-ethyl benzaldehyde. The precursor ion is produced by Schiff base reaction of 4-ATP and corresponding gasphase aldehyde molecule (1000 ppm). 

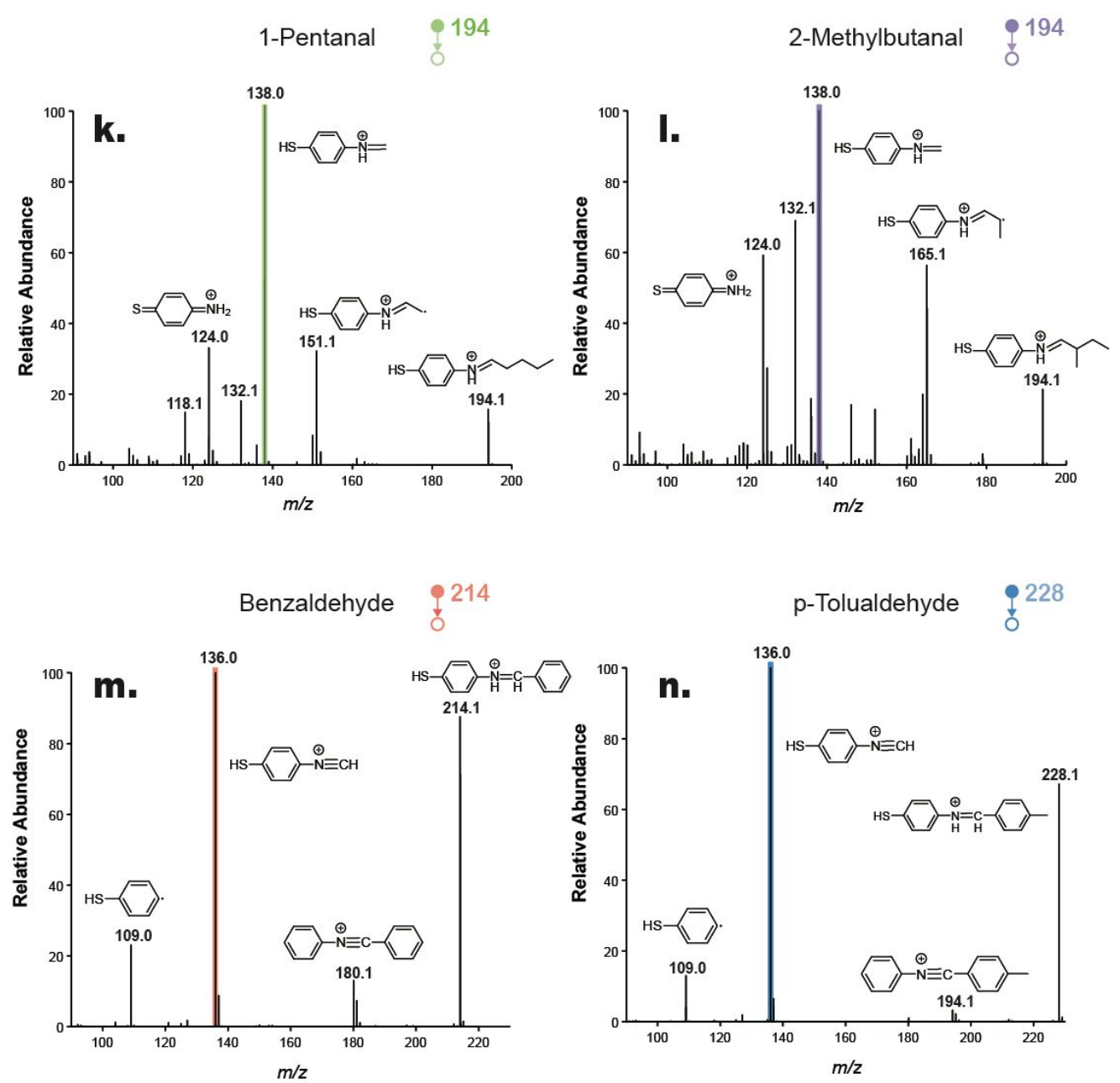

Figure S6-3. MS/MS spectra of (k) $\mathrm{m} / \mathrm{z} 194.1$ in the detection of 1-pentanal. (I) $\mathrm{m} / \mathrm{z} 194.1$ in the detection of 2-methylbutanal. (m) $m / z 214.1$ in the detection of benzaldehyde. (n) $m / z 228.1$ in the detection of $p$ tolualdehyde. The precursor ion is produced by Schiff base reaction of 4-ATP and corresponding gas-phase aldehyde molecule (1000 ppm). 
Table S1. MRM transitions of aldehydes tested in this work using the aldehyde test paper.

\begin{tabular}{|c|c|c|}
\hline $\begin{array}{l}\text { Aldehyde name and } \\
\text { structure }\end{array}$ & Product structure and $\mathrm{m} / \mathrm{z}$ & $\begin{array}{c}\text { Characteristic } \\
\text { fragment structure and } \\
\mathrm{m} / \mathrm{z}\end{array}$ \\
\hline$\stackrel{\stackrel{\mathrm{O}}{\mathrm{II}}-\mathrm{H}-\mathrm{H}}{\text { Formaldehyde }}$ & $\mathrm{H}_{2} \mathrm{C}=\stackrel{\oplus}{\mathrm{H}}$ & $\mathrm{H}_{3} \mathrm{~N}$ \\
\hline $\begin{array}{l}\mathrm{O} \\
\mathrm{H}-\mathrm{II} \\
\text { Acetaldehyde }\end{array}$ & $\mathrm{H}_{3} \mathrm{C}-\mathrm{HC}=\stackrel{\oplus}{\mathrm{H}}=\mathrm{SH}$ & $\mathrm{H}_{3} \mathrm{C}-\mathrm{C} \equiv \mathrm{N} \rightleftharpoons$ \\
\hline 1-Propanal & 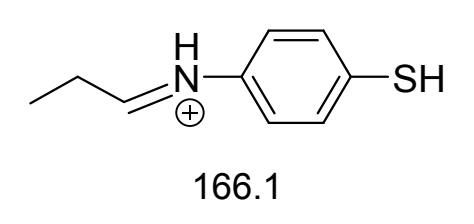 & $\mathrm{H}_{2} \stackrel{\oplus}{\mathrm{N}}=$ \\
\hline 1-Butanal & $\begin{aligned}= & \mathrm{N}-1 \\
& 180.1\end{aligned}$ & $\mathrm{HS}-\overbrace{138.0}^{\oplus}=$ \\
\hline 1-Pentanal & $=\stackrel{\mathrm{H}-\mathrm{N}}{194.1}$ & $\overbrace{138.0}^{\oplus}+{ }_{\mathrm{H}}^{\mathrm{N}}=$ \\
\hline 1-Hexanal & $=\underset{\oplus}{\stackrel{H}{N}-}$ & $\mathrm{HS}-\overbrace{138.0}^{\oplus} \underset{\mathrm{H}}{=}=$ \\
\hline
\end{tabular}




(-)ineptanal




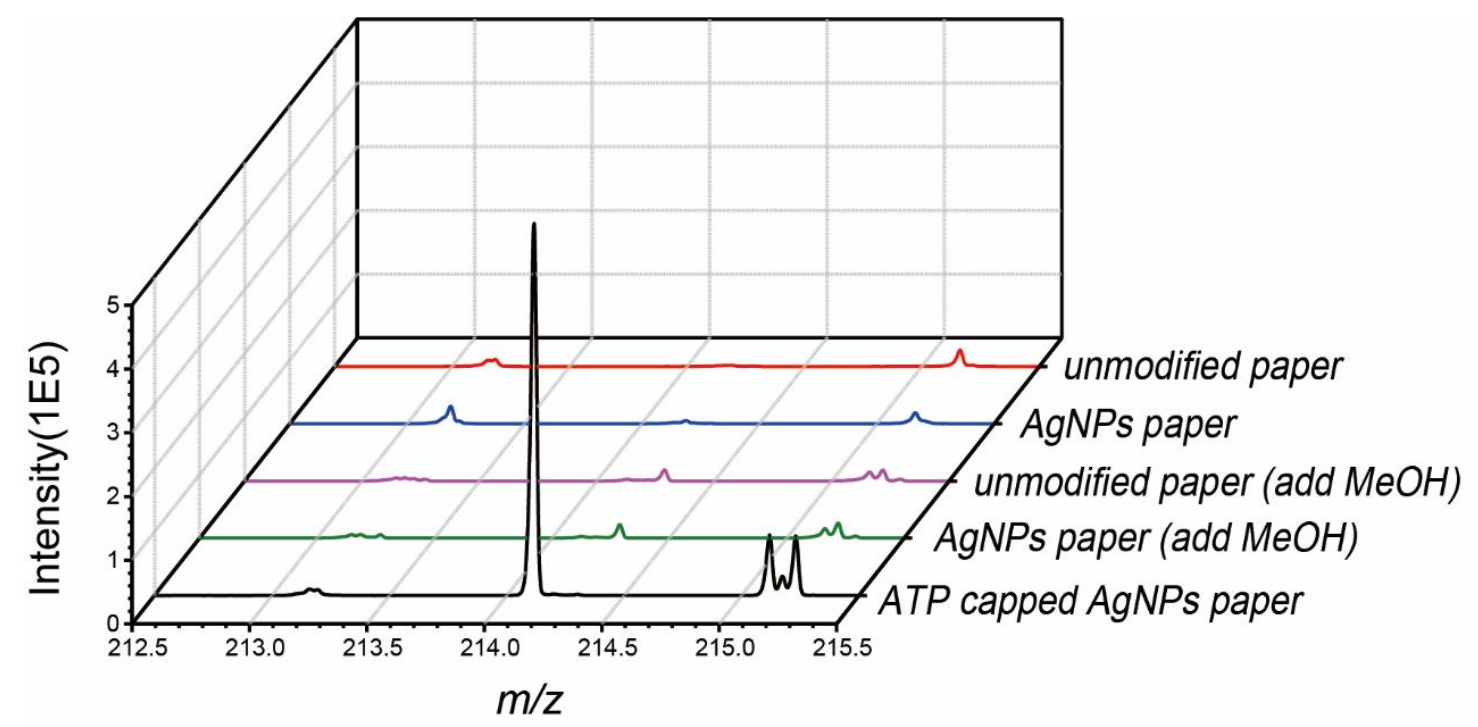

Figure S7. Comparison of mass spectrum of imine product of 4-ATP and benzaldehyde $(\mathrm{m} / \mathrm{z}=214.1)$ using unmodified paper (with or without $\mathrm{MeOH}$ solvent added on the paper), AgNPs paper (with or without $\mathrm{MeOH}$ solvent added on the paper) and ATP-capped AgNPs paper.10 ppb benzaldehyde was added for tested. Imine product of 4-ATP and benzaldehyde ( $\mathrm{m} / \mathrm{z} 214.1)$ can't be detected using unmodified paper and amine-lacking AgNPs paper. Similar results were observed with these control materials when methanol was added. On the contrary, imine product $(\mathrm{m} / \mathrm{z}=214.1)$ shows a strong peak when using aldehyde test paper where 4-ATP capped AgNPs are loaded on the paper for benzaldehyde detection. 
a.
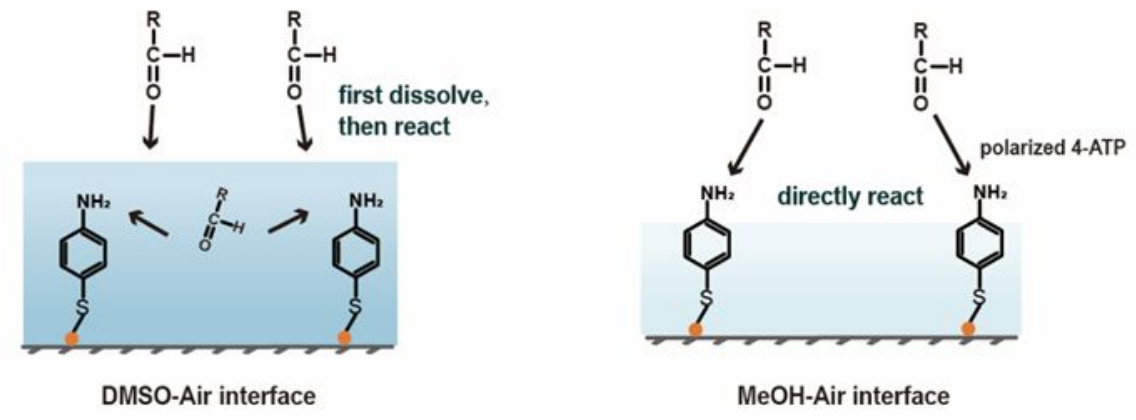

b.
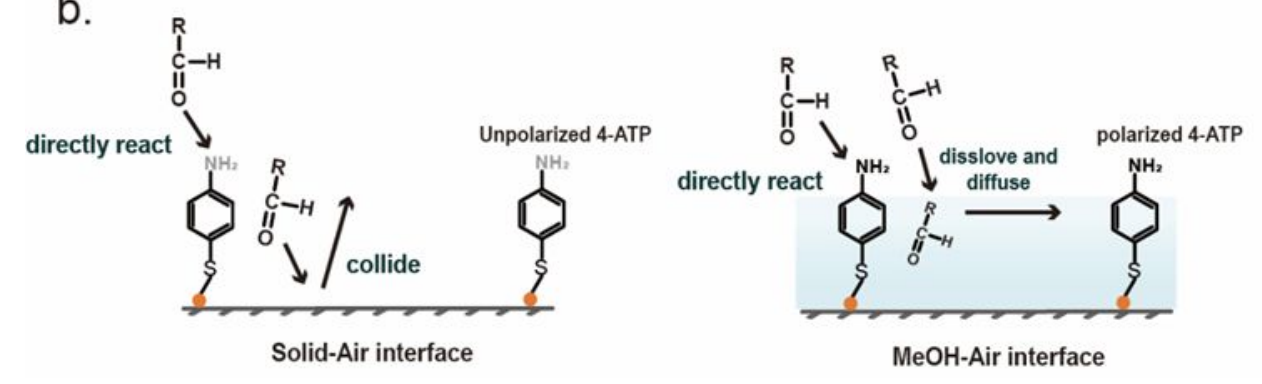

Figure S8. Scheme of probable reaction acceleration mechanism. a) Comparison of Schiff base reaction at DMSO-air interface and $\mathrm{MeOH}$-air interface. The nonvolatility property of DMSO solvent makes the reaction at DMSO-air interface inhibited. b) Comparison of Schiff base reaction at solid (paper substrate)air interface and $\mathrm{MeOH}$-air interface. The dissolution of aldehyde molecule and the polarization of ATP molecule of $\mathrm{MeOH}$ solvent may contribute to the reaction acceleration at $\mathrm{MeOH}$-air interface. 


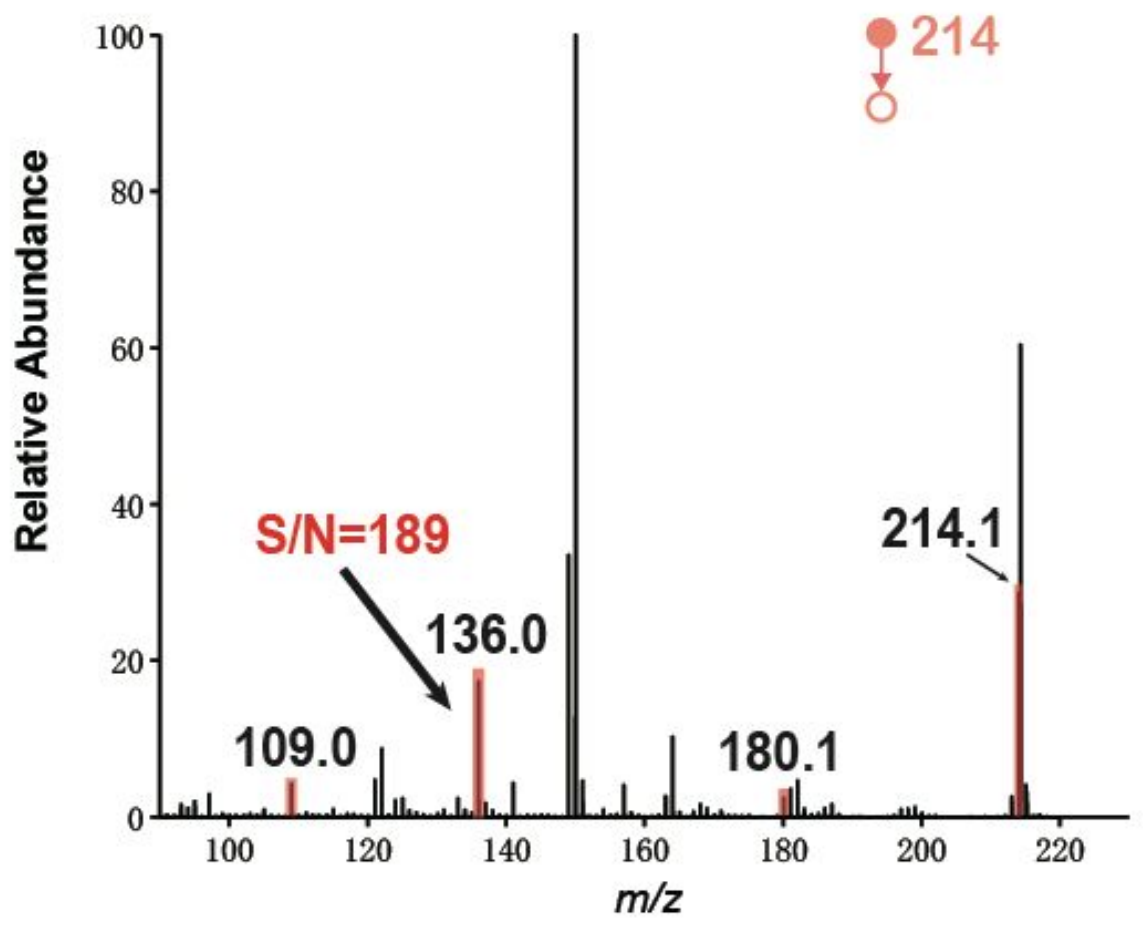

Figure S9. Result of 0.1 ppt gas-phase benzaldehyde tested by the EB aldehyde test paper in MRM mode. The characteristic fragment ion 136.0 still has a $\mathrm{S} / \mathrm{N}$ of 189. 

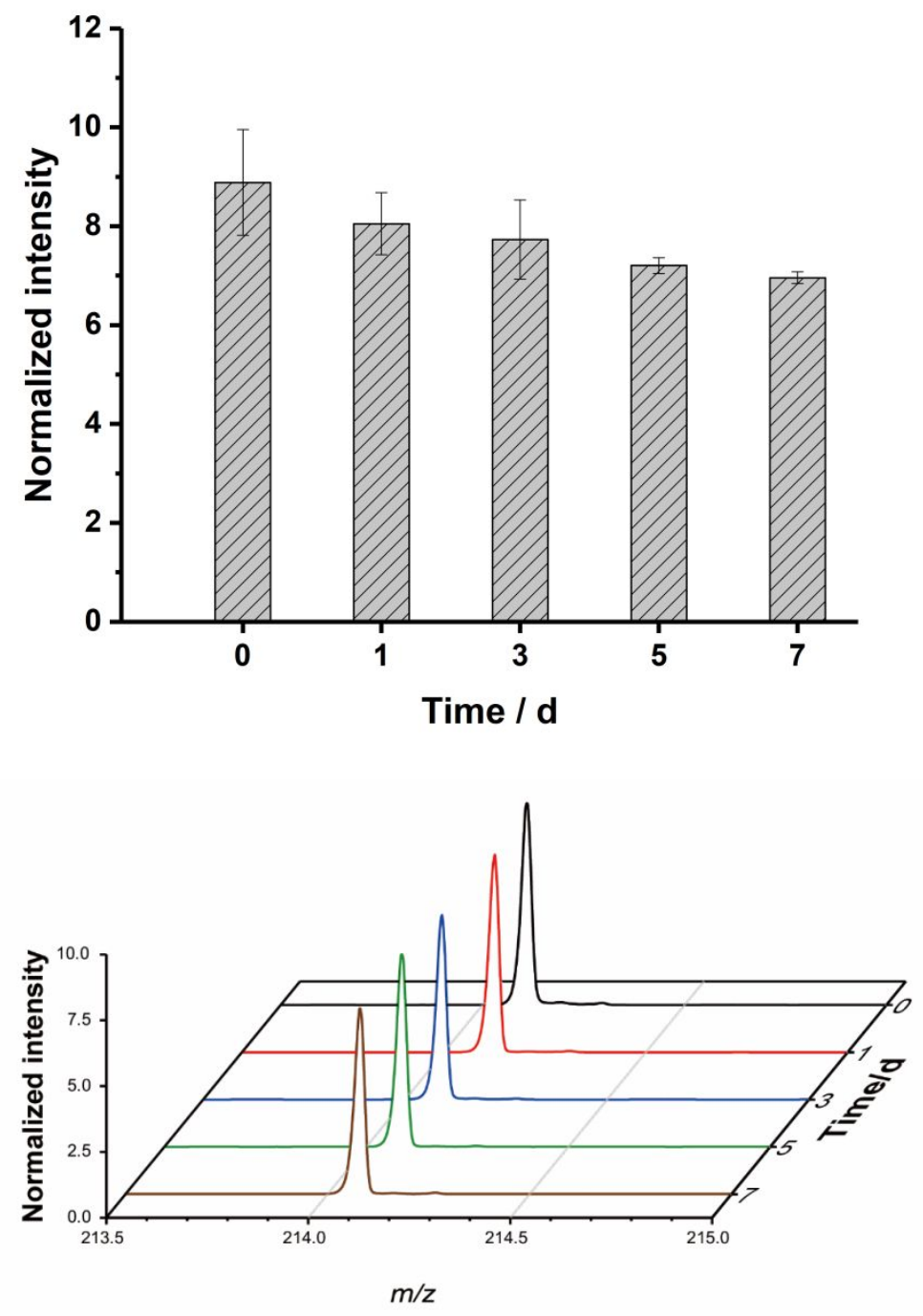

Figure S10. Robustness test of EB aldehyde test paper under $4{ }^{\circ} \mathrm{C}$ (up) and the corresponding mass spectra(bottom). The test paper can be stored at $4{ }^{\circ} \mathrm{C}$ for 7 days with slight intensity ratio decrease. $10 \mathrm{ppb}$ benzaldehyde and $100 \mathrm{ppt}$ IS was tested. Intensity ratios of ion peak m/z 214.1 to $\mathrm{m} / \mathrm{z} 228.1$ were calculated for robustness test. It shows a $\sim 21 \%$ drop over 7 day's storage in $4^{\circ} \mathrm{C}$, and a $\sim 13 \%$ drop in 3 days. Therefore, with current design of this aldehyde paper, it's better to keep the test paper at $-20^{\circ} \mathrm{C}$, but the storage and transportation of the test paper at $4{ }^{\circ} \mathrm{C}$ is also feasible if transport time is within 3 days. 
Table S2. Recovery test result of spiked-in benzaldehyde in exhaled breath by aldehyde test paper.

\begin{tabular}{|c|c|c|c|c|}
\hline Sample & Added/ppb & Avg found/ppb & Avg recovery & RSD (n=3) \\
\hline 1 & 9.08 & 8.38 & 0.923 & $5.12 \%$ \\
\hline 2 & 74.4 & 69.8 & 0.939 & $4.52 \%$ \\
\hline 3 & 692 & 683 & 0.987 & $1.07 \%$ \\
\hline
\end{tabular}



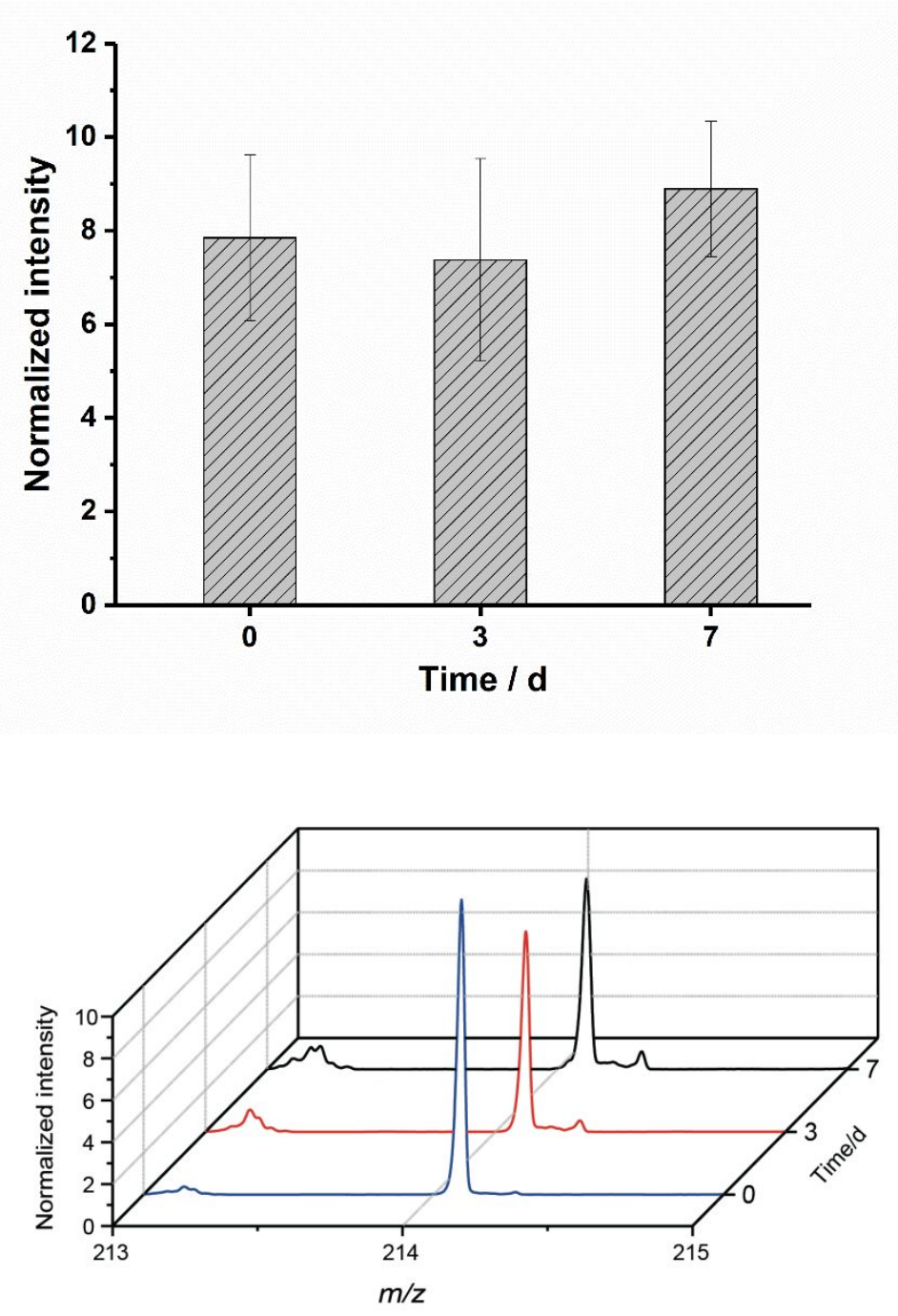

Figure S11. Robustness test of EB aldehyde test paper in aldehyde-added exhaled breath under $-20^{\circ} \mathrm{C}$ (up) and the corresponding mass spectra (bottom). The test paper can be stored at $-20{ }^{\circ} \mathrm{C}$ for 7 days with no obvious intensity ratio changes in the detection of aldehyde-added exhaled breath. Exhaled breath from healthy volunteer spiked with $10 \mathrm{ppb}$ benzaldehyde and $100 \mathrm{ppt}$ IS was tested. Intensity ratio of ion peak $\mathrm{m} / \mathrm{z} 214.1$ to $\mathrm{m} / \mathrm{z} 228.1$ was calculated and denoted for robustness test. 
Table S3. Clinical characteristics of the study samples for 6 patients with lung cancer in this study.

\begin{tabular}{|c|c|c|c|c|c|}
\hline No. & Gender & Age & Smoker(Y/N) & Ex-smoker(Y/N) & Histology \\
\hline 1 & Female & 32 & $\mathrm{~N}$ & $\mathrm{~N}$ & Adenocarcinoma \\
\hline 2 & Female & 53 & $\mathrm{~N}$ & $\mathrm{~N}$ & $\begin{array}{c}\text { Squamous Cell } \\
\text { Lung Carcinoma }\end{array}$ \\
\hline 3 & Female & 74 & $\mathrm{~N}$ & $\mathrm{~N}$ & Adenocarcinoma \\
\hline 4 & Female & 53 & $\mathrm{~N}$ & $\mathrm{~N}$ & Adenocarcinoma \\
\hline 5 & Male & 65 & $\mathrm{~N}$ & $\mathrm{Y}$ & Squamous Cell \\
& & Female & 64 & $\mathrm{~N}$ & $\mathrm{~N}$ \\
\hline 6 & & & & & Adenocarcinoma \\
\hline
\end{tabular}


Table S4. Significant difference between LC and control group by $t$ test.

\begin{tabular}{|c|c|c|c|c|c|}
\hline \multirow[b]{2}{*}{ Aldehyde } & \multirow[b]{2}{*}{ Group } & \multirow[b]{2}{*}{ mean } & \multirow[b]{2}{*}{ Standard deviation } & \multicolumn{2}{|c|}{ Student's t test } \\
\hline & & & & P-value & $\begin{array}{l}\text { significant } \\
\text { difference }\end{array}$ \\
\hline \multirow{2}{*}{ formaldehyde } & Control & 11.0364 & 3.7890 & \multirow{2}{*}{0.3341} & \multirow{2}{*}{$\mathrm{N}$} \\
\hline & LC & 10.1757 & 2.8788 & & \\
\hline \multirow{2}{*}{ acetaldehyde } & Control & 2.0116 & 0.3240 & \multirow{2}{*}{0.0092} & \multirow{2}{*}{$\mathrm{Y}$} \\
\hline & LC & 3.0920 & 0.8036 & & \\
\hline \multirow{2}{*}{ propanal } & Control & 0.1125 & 0.0141 & \multirow{2}{*}{0.0037} & \multirow{2}{*}{ Y } \\
\hline & LC & 0.1988 & 0.0615 & & \\
\hline \multirow{2}{*}{ butanal } & Control & 0.2578 & 0.0181 & \multirow{2}{*}{0.0043} & \multirow{2}{*}{$\mathrm{Y}$} \\
\hline & LC & 0.4088 & 0.1119 & & \\
\hline \multirow{2}{*}{ pentanal } & Control & 0.2258 & 0.0417 & \multirow{2}{*}{0.0050} & \multirow{2}{*}{$\mathrm{Y}$} \\
\hline & LC & 0.4249 & 0.1481 & & \\
\hline \multirow{2}{*}{ hexanal } & Control & 1.9752 & 0.3220 & \multirow{2}{*}{0.0094} & \multirow{2}{*}{$\mathrm{Y}$} \\
\hline & LC & 3.4228 & 1.2239 & & \\
\hline \multirow{2}{*}{ heptanal } & Control & 0.3782 & 0.0400 & \multirow{2}{*}{0.0261} & \multirow{2}{*}{$\mathrm{Y}$} \\
\hline & LC & 0.5409 & 0.1766 & & \\
\hline \multirow{2}{*}{ octanal } & Control & 2.4996 & 0.3147 & \multirow{2}{*}{0.0579} & \multirow{2}{*}{$\mathrm{N}$} \\
\hline & LC & 3.3498 & 1.1675 & & \\
\hline \multirow{2}{*}{ nonanal } & Control & 3.9595 & 0.5980 & \multirow{2}{*}{0.0261} & \multirow{2}{*}{ Y } \\
\hline & LC & 5.4556 & 1.4503 & & \\
\hline \multirow{2}{*}{ decanal } & Control & 0.7850 & 0.1785 & 01284 & \\
\hline & LC & 0.8986 & 0.1472 & 0.1284 & $\mathbf{N}$ \\
\hline honzoldabyds & Control & 1.8467 & 0.2986 & $000 ? 5$ & Y \\
\hline 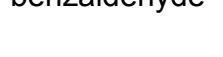 & LC & 3.003 & 0.6340 & 0.0020 & 1 \\
\hline ethyl & Control & 0.8915 & 0.1090 & 00001 & Y \\
\hline benzaldehyde & LC & 1.4573 & 0.1822 & 1. & 1 \\
\hline
\end{tabular}



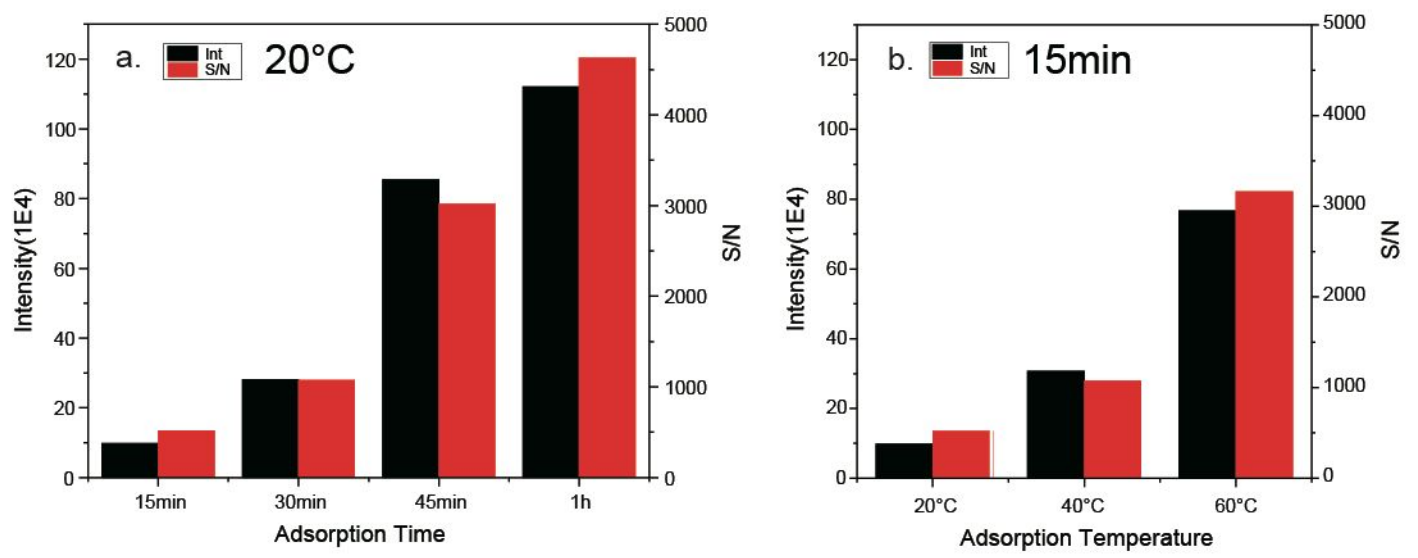

Figure S12. Influence of temperature and adsorption time on gas-phase aldehyde capture process for detection of benzaldehyde. The mass spectrum signal intensity (black) and signal to noise ratio (red) of characteristic fragment ion 136.0 under condition of a) constant temperature $\left(20^{\circ} \mathrm{C}\right)$. b) constant adsorption time (15 min). As is shown, aldehyde capture efficiency gradually increased with the elevation of temperature and reached the platform when adsorption time reached $45 \mathrm{~min}$. Raising the adsorption temperature to $60^{\circ} \mathrm{C}$ can also increase aldehyde capture efficiency and the final intensity and S/N result showed no obviously decrease. Previously published study ${ }^{3}$ also used $60{ }^{\circ} \mathrm{C}$ to be the proper reaction temperature. In order to balance capture time and sensitivity, we chose $60^{\circ} \mathrm{C}$ as reaction temperature and 15 minutes as adsorption time. 


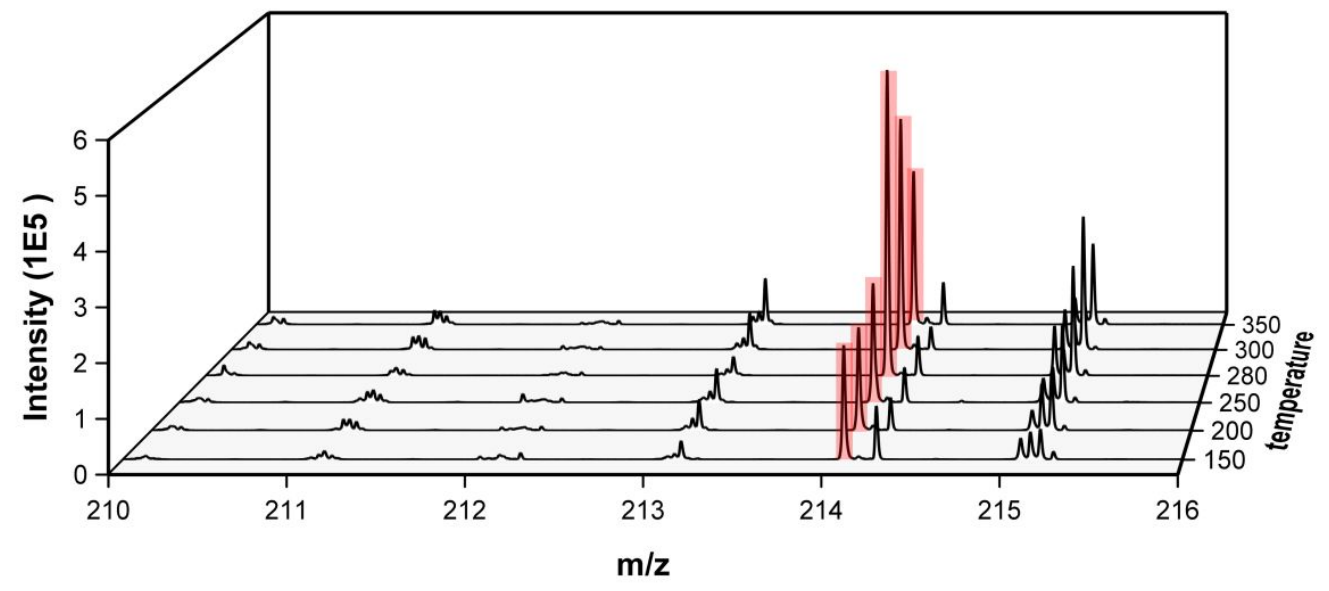

Figure S13. Comparison of mass spectrum of gas-phase benzaldehyde (1 ppm) detection with different MS dry gas temperature in MS inlet capillary. Dry gas temperature was also explored during MS detection process, for it influences droplet evaporation process. $280^{\circ} \mathrm{C}$ was the most proper temperature. 


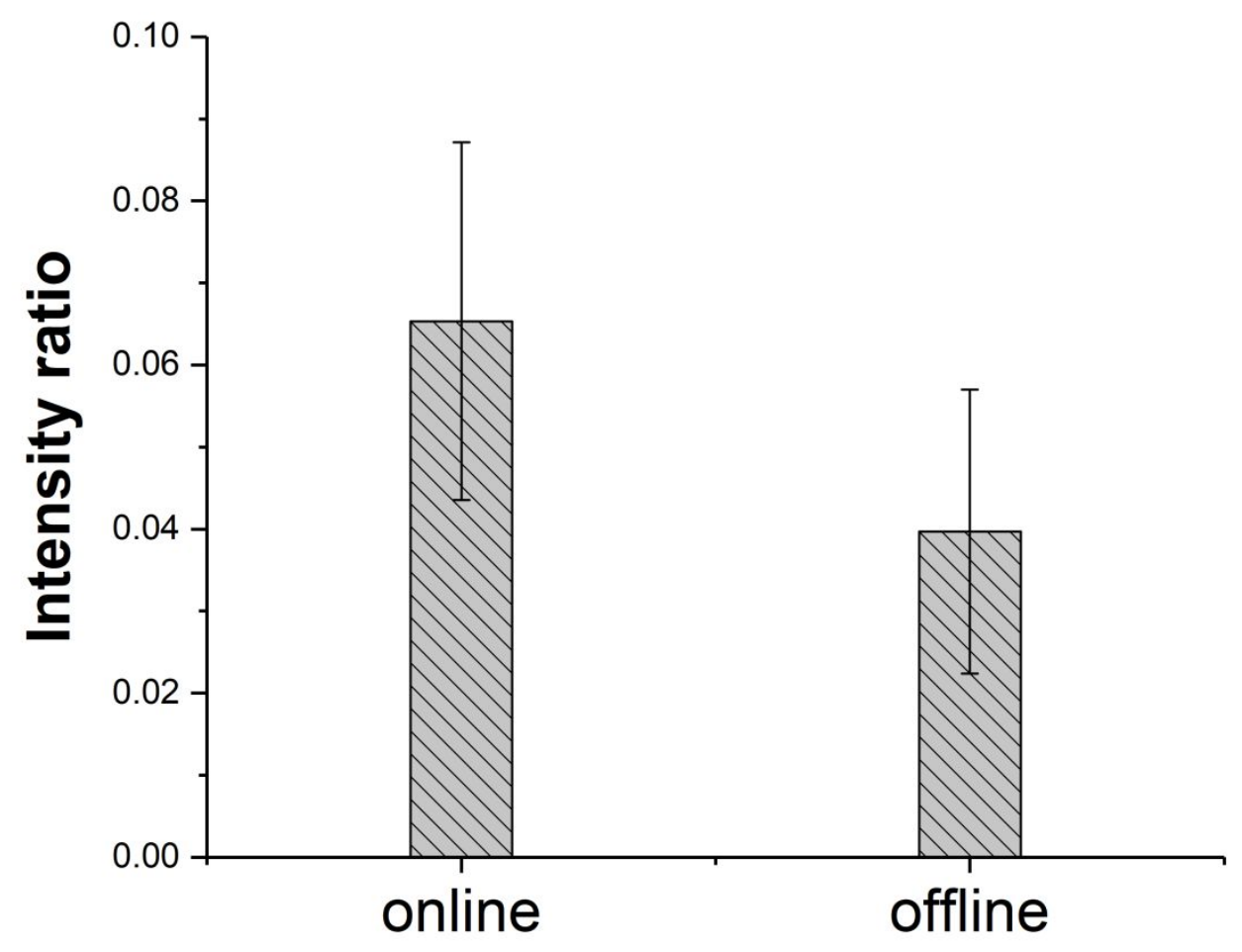

Figure S14. Comparison of paper spray ionization (online) and nanoESI (offline) in the detection of gasphase benzaldehyde by aldehyde test paper. For online paper spray ionization method, 1-dodecanethiol was added on the paper with DC voltage applied and the eluent was directly detected by paper spray MS. For offline nanoESI method, 1-dodecanethiol was added on the paper without DC voltage applied and the eluent was collected and detected by nanoESI MS. N,N-Dimethylethylenediamine (DMED) was used as internal standard for quantification. Intensity ratio of ion peak m/z 214.1 to $\mathrm{m} / \mathrm{z} 89.0$ (DMED) was calculated for comparison. It is shown that without DC voltage during elution, thiol displacement reaction could also occur. The result shows that thermodynamically driven mechanism is the main reason for thiol displacement reaction. 


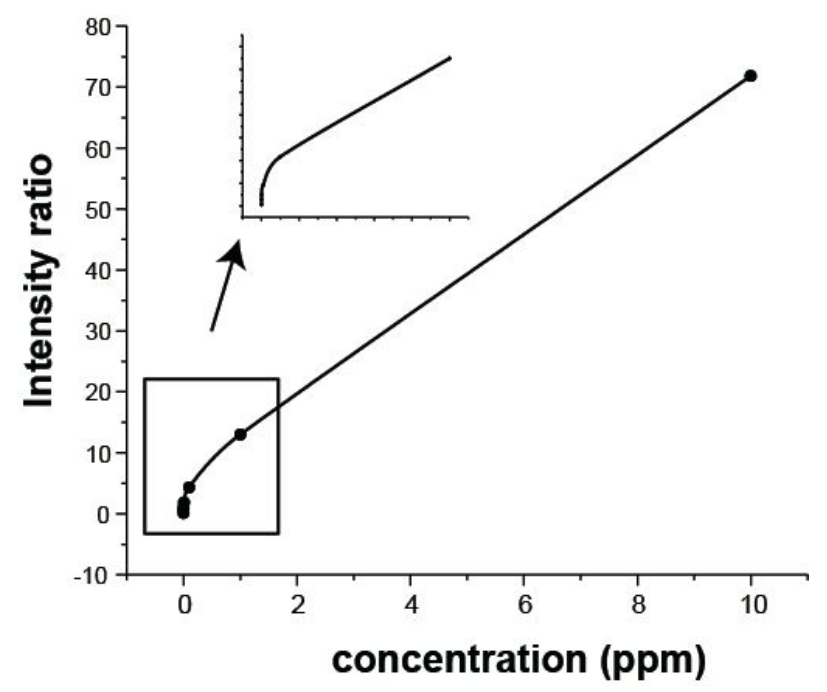

Figure S15. The adsorption curve of gas-phase benzaldehyde on the test paper. The concentration of benzaldehyde is from $10 \mathrm{ppt}$ to $10 \mathrm{ppm}$. Aldehyde with concentration of $1 \mathrm{ppm}$ (maximum aldehyde concentration of adsorption curve in Figure4b) has not reach the maximum binding capacity of the aldehyde test paper yet. In our adsorption model, aldehyde molecule is adsorbed by reacting with 4-ATP molecule. Only when aldehyde molecule was adsorbed by covalent binding with 4-ATP could the imine product ion be detected by MS. 


\section{References}

1. Sun, L.; Wei, G.; Song, Y.; Liu, Z.; Wang, L.; Li, Z., Fabrication of silver nanoparticles ring templated by plasmid DNA. Applied Surface Science 2006, 252 (14), 4969-4974.

2. Banerjee, S.; Zare, R. N., Influence of Inlet Capillary Temperature on the Microdroplet Chemistry Studied by Mass Spectrometry. J Phys Chem A 2019, 123 (36), 7704-7709.

3. Wei, Z.; Zhang, X.; Wang, J.; Zhang, S.; Zhang, X.; Cooks, R. G., High yield accelerated reactions in nonvolatile microthin films: chemical derivatization for analysis of single-cell intracellular fluid. Chem Sci 2018, 9 (40), 7779-7786. 